\title{
A Modified Deterministic Model for Reverse Supply Chain in Manufacturing
}

\author{
R. N. Mahapatra, ${ }^{1}$ B. B. Biswal, ${ }^{2}$ and P. K. Parida ${ }^{3}$ \\ ${ }^{1}$ Department of Mechanical Engineering, Institute of Technical Education and Research, SOA University, Bhubaneswar 751030, India \\ ${ }^{2}$ Department of Industrial Design, National Institute of Technology, Rourkela 769008, India \\ ${ }^{3}$ Department of Mechanical Engineering, National Institute of Technology, Rourkela 769008, India
}

Correspondence should be addressed to B. B. Biswal; bibhuti.biswal@gmail.com

Received 30 August 2012; Revised 9 December 2012; Accepted 10 December 2012

Academic Editor: Wen Chiung Lee

Copyright (C) 2013 R. N. Mahapatra et al. This is an open access article distributed under the Creative Commons Attribution License, which permits unrestricted use, distribution, and reproduction in any medium, provided the original work is properly cited.

\begin{abstract}
Technology is becoming pervasive across all facets of our lives today. Technology innovation leading to development of new products and enhancement of features in existing products is happening at a faster pace than ever. It is becoming difficult for the customers to keep up with the deluge of new technology. This trend has resulted in gross increase in use of new materials and decreased customers' interest in relatively older products. This paper deals with a novel model in which the stationary demand is fulfilled by remanufactured products along with newly manufactured products. The current model is based on the assumption that the returned items from the customers can be remanufactured at a fixed rate. The remanufactured products are assumed to be as good as the new ones in terms of features, quality, and worth. A methodology is used for the calculation of optimum level for the newly manufactured items and the optimum level of the remanufactured products simultaneously. The model is formulated depending on the relationship between different parameters. An interpretive-modelling-based approach has been employed to model the reverse logistics variables typically found in supply chains (SCs). For simplicity of calculation a deterministic approach is implemented for the proposed model.
\end{abstract}

\section{Introduction}

Gradual increase in the demand of goods has resulted in the reduction of nonrenewable resources with a high percentage of land fill of waste. This has shifted the modus operandi of supply chain, largely focusing on recovery options for the end of life products and products returned from various stages. Reverse logistics is the process of moving goods from their typical final destination for the purpose of capturing value or proper disposal. It is a process whereby supply chains can become more environments friendly through recycling and reusing thereby reducing the amount of virgin materials used. It is observed that all the sales transactions carried in many product-based supply chains are not final with the payment recovery at the point of sales. There is a need to cope up with returns of the product due to recalls, warranty claims, service returns, recovery at the endof-use disposal at the end-of-life, and so forth. Thus, the reverse distribution, which is from consumer to producer, has gained tremendous importance in the recent years. Reverse logistics stands for all the operations related to reuse of products coming back from customers, excess inventory of products and materials including collection, disassembly and processing of used products, product parts, and/or materials. This concept is complicated by the following typical figures on critical thinking.

(i) $50 \%$ of customers with bad return experience will not buy from the brand again.

(ii) In $60 \%$ of the cases the cost increase to process a returned product can be higher than value of product.

(iii) Data for returned products are not available or are not used for improving revenue, growth, and profitability.

(iv) Liability from noncompliance on waste regulations. 
These facts and figures make most of the successful companies focus on their core competencies-delighting customers through stellar forward supply chain. However, they experience a persistent lack of control over their reverse logistic processes leading to high cost, poor customer service, reduced asset recovery, low profitability, loss of shareholder value, and decreased competitiveness. Organizations and communities are forced to consider recovery alternatives such as reuse, repair, recycle, refurbish, remanufacture, and cannibalize, rather than discarding of the products after end of life. The different product recovery options are shown in Figure 1 . The product recovery processes aim to minimize the amount of waste sent to landfill sites by recovering materials and parts from old or obsolete products. Product recovery includes collection, disassembly, cleaning, sorting, repairing, reconditioning, reassembling, and testing Brennan et al. [1].

Product recovery and reuse of products and materials is not a new story. Waste paper recycling, metal scrap brokers, and deposit systems for soft drink bottles are all examples that are in practice since long. In all these cases the recovery of the used products is found to be economically more attractive than the disposal. Out of the different recovery options, this paper emphasizes on the remanufacturing of returned products that come back to the chain from various points. A model is developed which operates both on direct manufacturing as well as remanufacturing. In the mathematical model care has been taken to optimize the inventory level of direct manufacturing as well as that of the remanufacturing. The primary aim of the work is to the reutilize the resources and therefore it focuses on integration of the upstream and downstream chains. A generalized model for remanufacturing is shown in Figure 2. This model is a combination of direct manufacturing and remanufacturing.

The present study focuses on the deterministic approach of optimizing the reverse supply chain related to inventory control. Basically the model considers some of the parameters as known and constant ones for simplicity of calculation and tries to optimize the return quantities using different techniques.

\section{Related Work}

A supply chain is a network of facilities and distribution options that executes the functions of procurement of materials, conversion of these materials into intermediate and finished products, and the distribution of these finished products to customers. Supply chains exist in both service and manufacturing organizations, although the complication of the chain may vary greatly from industry to industry and organization to organization. The literature review, for the sake of clear understanding of this paper, is divided into two distinct divisions: forward supply chain and reverse supply chain with specific orientation towards inventory control.

\section{Forward Supply Chain}

Much has been said in the past and research is still going on the effectiveness of the forward supply chain. According to Frankel [2] more emphasis should be given on the key components (supplier, manufacturing, and customer) and factors responsible for successful collaboration of supply chain to make the forward supply chain effective. The factors considered for this purpose are: willingness to innovate and change, understanding other's business laying down, common goals and objectives, choosing appropriate measures and incentives, and sharing of information.

The ability of supply chain members to successfully design and execute solutions that facilitate inventory arriving on time (in the proper condition, at the proper location, and to the proper customer/consumer) is critical to developing efficient supply chains. Arshinder et al. [3] has stressed upon the coordination between various members of the supply chain. Supply chains are generally complex and are characterized by numerous activities spread over multiple functions which differ from organizations to organizations. Therefore, it becomes a challenge for effectively coordinating the supply chain. In the paper, the coordination mechanism is elaborately discussed with the gaps in the coordination process. An empirical case study has been conducted and the difficulty in SC coordination is expressed through a fish bone diagram. The authors conclude that the Supply chain coordination (SCC) problems could be due to the conflicting objectives that leads to a short time relationships with SC members, hence the environment and expectations changes frequently with addition of new members. Hence the SC members must work towards a unified system and coordinate with each other. Silver [4] investigated and presented a tutorial overview of inventory management. In this paper the author tried to categorize the inventory problems and associated models based on dimensions. He concluded that there exists a continuing gap between theory and practice of SC pertinent to inventory management and suggested a number of research topics that will bridge the gap. Alfares [5] has presented a model of an inventory system with stock-dependent demand, in which the holding cost is a step function of storage time. Two types of holding cost variation in terms of storage time have been considered. These are: retroactive increase, and incremental increase. Simple optimization algorithms have been developed, and numerical examples have been solved. From the analysis he concluded that both the optimal order quantity and the cycle time decrease when the holding cost increases.

An extensive study shows that while some researchers are emphasizing on the effectiveness of the SC with key components and factors others are interested on SSC. Some research work focuses on the cost reduction by optimizing the order quantity. From the above discussion it is clear that SC effectiveness depends on a wide range of decisions. The decision to be most effective depends on the type of organization and the business environment.

\section{Reverse Supply Chain}

Reverse supply chain is all about coordination and control, physical pickup and delivery of the material, parts, and products from the field to reuse, repair, recycle, refurbish, remanufacture, cannibalize, and subsequent returns to the 


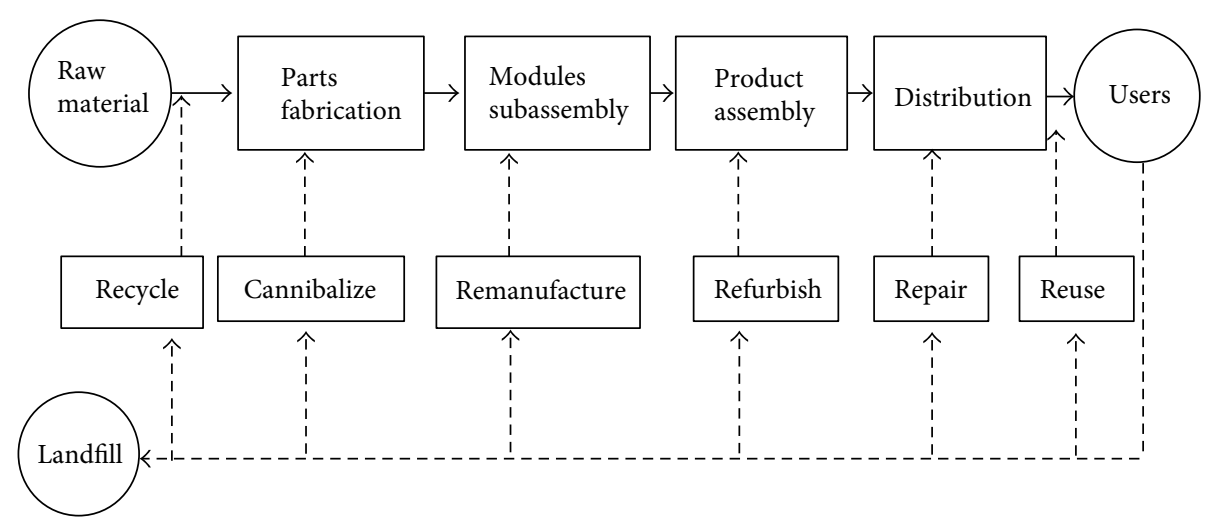

FIgURE 1: Product recovery options.

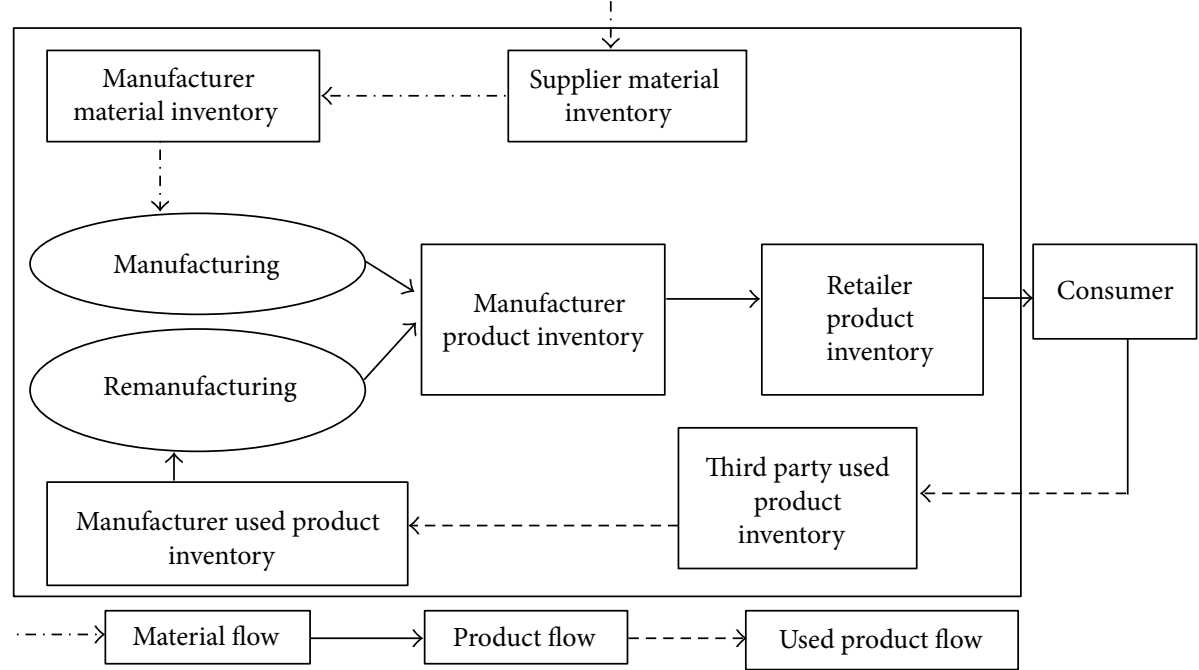

FIGURE 2: A generalized model for remanufacturing.

field where appropriate further action can be taken to include them again in the mainstream of the supply chain.

\subsection{Repair and Recycle. Dobos and Richter [6] has analyzed} a production-recycling system. His analysis consists of two types of models. The first model is related to minimization of the EOQ related costs and the second one is the generalization of the first model with linear waste disposal, recycling, production, and buyback costs. According to the author, the pure strategy (either production or recycling) is optimal when compared with the mixed strategy. If these pure strategies are not technologically feasible and some used products do not return or even more as the sold ones will come back, and some of them are not recycled, then the option is to adopt the mixed strategy with some upper bound on the buyback rate. Oh and Hwang [7] considered a recycling system where the supplier receives a fixed portion of recyclable material from customers. Like used cans and crashed bottles, recyclable materials become raw materials of new ones. In order to meet the demand, he also purchases additional raw material from outside. He did find out the optimal solution by considering/comparing the total cost. The order quantity, production setup, and the production lot are optimized based on minimization of the total cost. Koh et al. [8] obtained the economic order quantity (EOQ) for newly produced products and the optimal inventory level of recoverable items to start the recovery process simultaneously in a joint EOQ and EPQ model. According to the relationship with the parameters, a numerical model is proposed with one setup for recovery (or one order for new products) and many order for new products (or many setups for recovery). The system was modeled under four situations and a solution procedure is established to find out the optimal control parameters. A more clear study is carried out by Mabini et al. [9] in the field of repairable inventory. The authors considered two different situations and the approach is similar to EOQ model formulation. The first one is the single-item with a fixed and known scrapping rate and ample repair capacity. The second one is the modified form of the first which account for multiple items that share a common and limited repair capacity. From the above study one can get important relationships between serviceable 
and nonserviceable inventory levels, between replenishment quantities and the specified service level, or among multiple items competing for a limited repair capacity. Richter [10] modeled a situation where some share of the used products is collected and later repaired; the other products are disposed outside according to certain waste disposal rate. This model is extended to the case of variable setup numbers $n$ and $m$ for production and repair within some collection time interval. Richter [11] studied an EOQ model in which the stationary demand can be satisfied by newly made products and by repaired products. This model assumes that the used products are collected and later repaired at some rate and the other products might be disposed outside according to some waste disposal rate. This model extends previous studies to the case of variable setup numbers $\mathrm{n}$ and $\mathrm{m}$ for production and repair within some variable collection time interval.

4.2. Remanufacturing. Teunter and Vlachos [12] studied a single item hybrid production system with manufacturing and remanufacturing. It is assumed that remanufacturing is profitable and when, there are more demands than returns. Teunter and Vander Laan [13] provided a DCF (discounted cash flow) inventory model with disposal and remanufacturing. It is of common use to add the discount rate times the capital tied up in a product, to the out-of-pocket holding cost rate. The author suggest that, one should be very careful while applying the average cost approach for more complex models with remanufacturing and disposal as no set of holding cost rate will lead to DCF optimal. Richter and Sombrutzki [14] discussed the reverse Wagner/Whitin's dynamic production planning and inventory control model and some of its extensions. The model can efficiently deal with several combinations of reverse and original models. The restriction of the proposed model is that if the quantity of used products does not match the demand of remanufactured goods, the model fails. Therefore the design of appropriate algorithms seems to be another important research direction. Chung et al. [15] analyzed an inventory system with traditional forward-oriented material flow as well as a reverse material flow supply chain. In the reverse material flow, the used products are returned, remanufactured and shipped to the retailer for resale. A multi-echelon inventory system with remanufacturing capability is proposed. The authors tried to maximize the joint profits of the supplier, the manufacturer, the third-party recycle dealer and the retailer under contractual design. The analytical results of this study show a substantial profit increase using the integrated approach.

The objective of the present work is to provide an approachable model which in future may replace the existing model with uniform demand rate, finite production rate, and with shortages allowed. This particular study is directed towards stabilizing the diversified opinions in the field of returned item inventory. In most of the cases, the models are deterministic. The approach here is a different from the models discussed earlier in the sense that the returned item inventory is being used as a substitute to stock out conditions. The primary concern of this work is environmental benefits where use of return items will decrease the depletion rate of resources. Successful implementation of the method can reduce the inventory cost of finished goods. An example problem has been discussed to illustrate the capability of the model.

\section{The Conventional Inventory Model}

Considering a manufacturing scenario, the conventional model of inventory shown (in Figure 3) has a finite production rate. In this model, the inventory is zero at the beginning. The finished product inventory increases at a constant rate $(K-R)$ for time $T_{1}$ until it reaches a level $I_{m}$. There is no replenishment during time $T_{2}$. Inventory decreases (as it is shipped out or used internally) at a constant rate $R$ till it becomes zero. Shortage starts filling up at a constant rate $R$ during time $T_{3}$ (as there is no manufacturing) until this backlog reaches a level $S_{\max }$. At the beginning of time $T_{4}$, manufacturing starts and backlog is filled at a constant rate $K-R$ till the backlog becomes zero at the end of period $T_{4}$. This completes the cycle.

\section{The Model Variables}

$q=$ manufactured quantity during the cycle, $K$ = rate of production (units/year), $R$ = rate of consumption (units/year), $C_{1}=$ holding cost during the time interval $T$ (Rs/unit/year), $C_{2}=$ shortage cost during time interval $T$ (Rs/unit/year), $C_{3}$ $=$ setup cost per setup.

The total time is given by

$$
T=T_{1}+T_{2}+T_{3}+T_{4} .
$$

The total cost per unit time can be computed as follows:

Total cost $=C$

$$
\begin{aligned}
=( & \frac{1}{2} C_{1} \times I_{m} \times\left(T_{1}+T_{2}\right)+\frac{1}{2} C_{2} \times S \\
& \left.\times\left(T_{3}+T_{4}\right)+C_{3}\right)\left(T_{1}+T_{2}+T_{3}+T_{4}\right)^{-1} .
\end{aligned}
$$

It can be shown that

$$
\begin{aligned}
I_{m} & =q\left(1-\frac{R}{K}\right)-S, \\
T_{1}+T_{2} & =\frac{I_{m}}{K-R}+\frac{I_{m}}{R} \\
\Longrightarrow T_{1}+T_{2} & =I_{m}\left(\frac{1}{K-R}+\frac{1}{R}\right) \\
\Longrightarrow T_{1}+T_{2} & =\left\{q\left(1-\frac{R}{K}\right)-S\right\}\left(\frac{1}{K-R}+\frac{1}{R}\right),
\end{aligned}
$$

also

$$
\begin{aligned}
T_{3}+T_{4} & =\frac{S}{K-R}+\frac{S}{R} \\
\Longrightarrow T_{3}+T_{4} & =S\left(\frac{1}{K-R}+\frac{1}{R}\right) .
\end{aligned}
$$




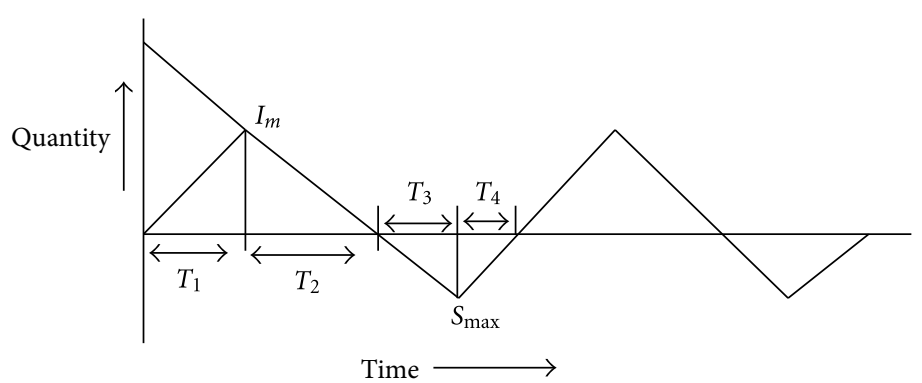

Costs:
• Holding cost
- Procurement cost
- Shortage cost
Other considerations:
- Demand rate
- Consumption rate
- Cycle time $T_{1}+T_{2}+T_{3}+T_{4}$

FIGURE 3: A model with uniform demand rate, finite production rate, and shortages allowed.

Hence,

$$
T_{1}+T_{2}+T_{3}+T_{4}=\frac{q}{R}
$$

Now substituting $\left(T_{1}+T_{2}\right),\left(T_{3}+T_{4}\right), T_{1}+T_{2}+T_{3}+T_{4}$, and $I_{m}$ in (2) for total cost and using $\partial C / \partial q=0$, we get

$$
q_{\text {optimal }}=\sqrt{2 C_{3} \times \frac{C_{1}+C_{3}}{C_{1} \times C_{2}}} \times \sqrt{\frac{K \times R}{K-R}} .
$$

However, this model is bound to have stock outs which may lead to disturbance in the committed delivery schedule and hence customer dissatisfaction. Further, the model uses virgin raw materials for production which calls for more investment on acquiring the materials as well as its processing requirements.

\section{The Proposed Model}

This model as shown in Figure 4 can be a substitute for the inventory models where stock outs are allowed. The stock out part for the existing model is replaced by the products from remanufacturing. The total cycle time is taken as " $t$ ". There are two cycles operating at the same time (one is remanufacturing cycle which is shown at the bottom and the second one is the direct manufacturing with remanufactured items which is shown on the top).

In the remanufacturing cycle the products having potential to be remanufactured are collected back at a rate $f$. $d$ where $f$ is the fraction of return and $d$ is the demand rate. The value of " $f$ " may vary between 0 and 1 whereas that of " $d$ " depends on the market demand. The rate of remanufacturing needs to be decided in such a manner
TABLE 1: The values of $S, I_{m}$, and total cost with variation of fraction returned.

\begin{tabular}{lccc}
\hline$f$ & $S$ & $I_{m}$ & TC \\
\hline 0.1 & 176 & 615 & 7288 \\
0.2 & 277 & 555 & 6923 \\
0.3 & 344 & 517 & 6684 \\
0.4 & 393 & 491 & 6515 \\
0.5 & 429 & 472 & 6388 \\
0.6 & 457 & 458 & 6290 \\
0.7 & 480 & 447 & 6211 \\
0.8 & 500 & 437 & 6147 \\
0.9 & 516 & 430 & 6093 \\
\hline
\end{tabular}

that it reaches the maximum level " $S$ " at the end of the cycle time " $t$ ". The whole lot of remanufactured products is transferred to the direct manufacturing cycle at this point of time for satisfying the market demand. An inventory level of the remanufactured products becomes zero, the next remanufacturing cycle begins.

In the proposed model the cycle of direct manufacturing is supplemented with remanufactured items. During the time " $t_{1}$ " all the remanufactured products are consumed and the finished product inventory comes down to zero. At the beginning of time " $t_{2}$ ", direct manufacturing starts with a rate " $p$ " and at the same time the market demands are satisfied with a rate " $d$ ". The inventory level of finished products rises at a rate $(p-d)$ and attains a value " $I_{m}$ " at the end of period " $t_{2}$ ". At the beginning of the period " $t_{3}$ " the direct manufacturing is stopped and market demand is satisfied from the stock of inventory of finished products. At the end of the period " $t_{3}$ " the stock level comes down to zero. By this 
time, the stock of finished products in the remanufactured cycle are carried over to the cycle of direct manufacturing with remanufactured items and process continues

The silver line on the proposed model is that, the disadvantages associated in the conventional model (where stock outs are allowed) are completely eliminated. As the model uses remanufacturing of recovered products, there is a decrease in the total cost and there will be an increase in the productivity. Since returned items are remanufactured to fill out for raw material inventories, there is a substantial environmental benefit as it controls the depletion rate of resources to a great magnitude. Additionally, the possibility of loss of goodwill from the customers resulting from stock outs is completely eliminated in the proposed model. The primary concern is environmental benefits where the use of return items will decrease the depletion rate of resources. Successfully implementing the method can reduce the cost of finished goods. This helps in reduction of the raw material supplies.

\section{The Variables for the Proposed Model}

The following are the variables used for the model:

$D=$ annual demand for the item, $d=$ the demand rate/consumption rate for the item, $p=$ the rate of production/procurement of the finished product in direct manufacturing, $f=$ fraction of the demand rate that is used for remanufacturing, $C_{1}=$ holding cost for the finished goods in direct manufacturing as well as in remanufacturing, $C_{2}$ $=$ holding cost for the goods in remanufacturing cycle, $C_{0}$ = order cost/set up cost for direct manufacturing, $C_{0}^{1}=$ order cost/set up cost for remanufacturing, $I_{m}=$ maximum level of the finished products in direct manufacturing, $S=$ maximum level of the finished products in remanufacturing, $t$ $=$ cycle time, $t_{1}=$ time in which remanufactured products are consumed, $t_{2}=$ time during which inventory buildup takes place in direct manufacturing, $t_{3}=$ time in which inventory level for direct manufacturing comes to zero.

The model, on mathematical analysis, gives out the following parameters.

(a) Holding cost for finished goods inventory

$$
\begin{aligned}
& =C_{1} \times(\text { Area OAB })+C_{1} \times(\text { Area BCD }) \\
& =C_{1} \times \frac{1}{2} S t_{1}+C_{1} \times \frac{1}{2} I_{m} \times\left(t_{1}+t_{2}\right) \\
& =\frac{C_{1} S t_{1}}{2}+\frac{C_{1} I_{m}\left(t_{1}+t_{2}\right)}{2} \\
& \Longrightarrow \text { Holding cost for finished goods inventory: } \\
& =\left[\frac{C_{1} S t_{1}}{2}+\frac{C_{1} I_{m}\left(t_{1}+t_{2}\right)}{2}\right] .
\end{aligned}
$$

(b) Holding cost for remanufactured :

$$
\text { goods inventory }=\frac{1}{2} \times f d t^{2} \times C_{2} \text {. }
$$

(c) Number of set ups $=\frac{D}{\left(I_{m}+S\right)}$

$\Rightarrow$ set up cost for finished goods inventory

$=C_{0} \times \frac{D}{\left(I_{m}+S\right)}$.

(d) Set up cost for remanufactured

$$
\text { goods inventory }=C_{0}^{1} \times \frac{D}{\left(I_{m}+S\right)} .
$$

Therefore, the annual total cost of inventory

$$
\begin{aligned}
(\mathrm{TC})= & {\left[\frac{C_{1} S t_{1}}{2}+\frac{C_{1} I_{m}\left(t_{1}+t_{2}\right)}{2}\right]+\frac{1}{2} \times f d t^{2} \times C_{2} } \\
& +C_{0} \times \frac{D}{\left(I_{m}+S\right)}+C_{0}^{1} \times \frac{D}{\left(I_{m}+S\right)} .
\end{aligned}
$$

The following parameters can be derived from the model

$$
\begin{gathered}
S=d t_{1}, \\
S=f d t \Longrightarrow t=\frac{S}{f d} .
\end{gathered}
$$

From (10),

$$
\begin{gathered}
f \cdot t=t_{1}, \\
t_{2}=\frac{I_{m}}{(p-d)}, \\
I_{m}=d t_{3} .
\end{gathered}
$$

From (12) and (13),

$$
\begin{aligned}
d t_{3}=(p-d) t_{2} & \Longrightarrow d\left(t_{2}+t_{3}\right)=p t_{2} \\
& \Longrightarrow\left(t_{2}+t_{3}\right)=\frac{p}{d} \times t_{2} .
\end{aligned}
$$

Substituting these values in (9) for total cost, we have

$$
\begin{aligned}
\mathrm{TC}= & \frac{C_{1} S f t}{2}+\frac{C_{1} I_{m} p t_{2}}{2 d}+\frac{C_{2} f d t^{2}}{2}+C_{0} \times \frac{D}{\left(I_{m}+S\right)} \\
& +C_{0}^{1} \times \frac{D}{\left(I_{m}+S\right)} \\
\Longrightarrow \mathrm{TC}= & \frac{C_{1} S^{2}}{2 d}+\frac{C_{1} p}{2 d(p-d)} \times I_{m}^{2}+\frac{C_{2} S^{2}}{2 f d} \\
& +\frac{D}{\left(I_{m}+S\right)}\left(C_{0}+C_{0}^{1}\right) \\
\Longrightarrow \mathrm{TC}= & \frac{S^{2}}{d}\left(\frac{C_{1}}{2}+\frac{C_{2}}{2 f}\right)+\frac{C_{1} p}{2 d(p-d)} \times I_{m}^{2} \\
& +\frac{D}{\left(I_{m}+S\right)}\left(C_{0}+C_{0}^{1}\right) .
\end{aligned}
$$




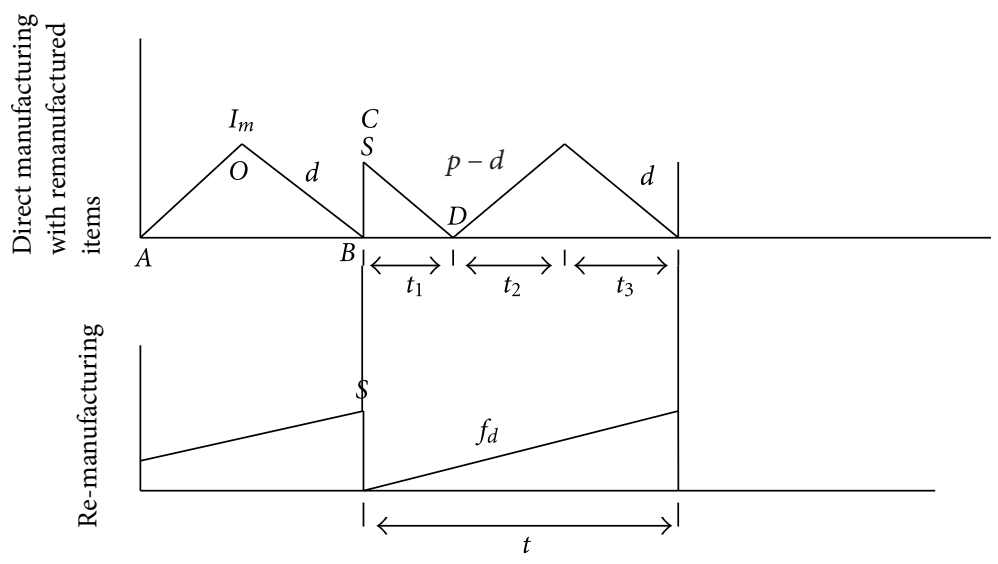

FIGURE 4: The proposed model with remanufacturing.

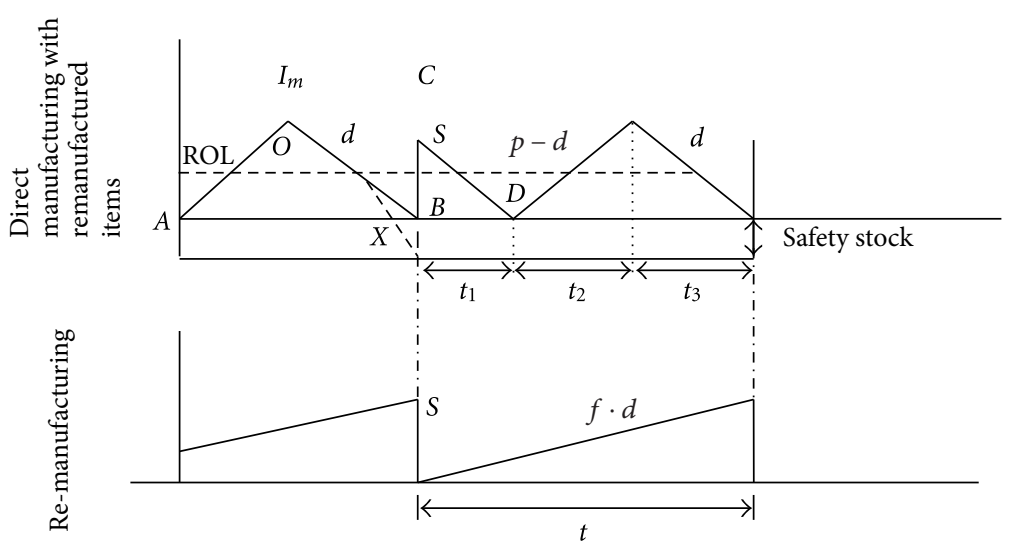

FIGURE 5: The inventory model considering safety stock.

Equation (15) clearly shows that the total cost is a function of $C_{1}, S, d, p, I_{m}, C_{2}, f, D, C_{0}$, and $C_{0}^{1}$. Out of these $C_{1}, d, p, C_{2}$, $f, D, C_{0}$, and $C_{0}^{1}$ are constants and are assumed to be known. The values of $S$ and $I_{m}$ can be found by minimizing the total cost function. Therefore using

$$
\frac{\partial T C}{\partial I_{m}}=0, \quad \frac{\partial T C}{\partial S}=0
$$

we can get the maximum levels of finished products through direct manufacturing $\left(I_{m}\right)$ and that through the remanufacturing $(S)$.

Considering $\partial T C / \partial I_{m}=0$, we have

$$
\begin{aligned}
& \frac{2 I_{m} C_{1} p}{2 d(p-d)}-\frac{D\left(C_{0}+C_{0}^{1}\right)}{\left(I_{m}+S\right)^{2}}=0 \\
& \Longrightarrow \frac{2 I_{m} C_{1} p}{2 d(p-d)}=\frac{2 S}{d}\left(\frac{C_{1}}{2}+\frac{C_{2}}{2 f}\right) \\
& \Longrightarrow I_{m}=\frac{2 S(p-d)}{C_{1} p}\left(\frac{C_{1}}{2}+\frac{C_{2}}{2 f}\right) .
\end{aligned}
$$

Now using $\partial \mathrm{TC} / \partial S=0$, we can have

$$
\begin{aligned}
& \frac{2 S}{d}\left(\frac{C_{1}}{2}+\frac{C_{2}}{2 f}\right)-\frac{D\left(C_{0}+C_{0}^{1}\right)}{\left(I_{m}+S\right)^{2}}=0 \\
& \frac{2 S}{d}\left(\frac{C_{1}}{2}+\frac{C_{2}}{2 f}\right)-\frac{D\left(C_{0}+C_{0}^{1}\right)}{\left(I_{m}+S\right)^{2}}=0 \\
& \Rightarrow \frac{2 S}{d}\left(\frac{C_{1}}{2}+\frac{C_{2}}{2 f}\right)=\frac{D\left(C_{0}+C_{0}^{1}\right)}{\left(I_{m}+S\right)^{2}} .
\end{aligned}
$$

Substituting the value of $I_{m}$ from (17) in (18), we get

$$
\frac{2 S}{d}\left(\frac{C_{1}}{2}+\frac{C_{2}}{2 f}\right)=\frac{D\left(C_{0}+C_{0}^{1}\right)}{\left[\left(2 S(p-d) / C_{1} p\right)\left(C_{1} / 2+C_{2} / 2 f\right)+S\right]^{2}}
$$

Simplifying the above equation we can have

$$
S=\left[\frac{D\left(C_{0}+C_{0}^{1}\right) \times 4 C_{1}^{2} p^{2} f^{3} d}{\left[2(p-d)\left(C_{1} f+C_{2}\right)+2 C_{1} p f\right]^{2} \times\left(C_{1} f+C_{2}\right)}\right]^{1 / 3} .
$$




\section{Use of Safety Stock to Avoid the Stock out due to Change in the Demand}

It is of great importance to consider the stock out condition in the direct manufacturing part of the cycle due to the variation of the demand rate. The model considering the stock is shown in Figure 5. It is shown as a dotted line, indicating higher demand in the triangle AOB. Because of the higher demand the zero stock condition will occur at $X$ instead of $B$ (refer Figure 5). Therefore the need of a safety stock is essential to cope up with this kind of situation. The safety stock can be calculated by using the concept of service level. We set the service level to a very high value (more than 90\%) which means that out of 100 times we face such situation we shall be able to supply the items from the stock at least 90 times.

The safety stocks can be determined as

$$
\text { Safety Stock }=z \sigma_{L},
$$

where $Z=$ number of standard deviations for a specified service level, which can be directly used from the normal distribution table (e.g., service level 95\% means that $Z=$ 1.65), and $\sigma_{L}=$ the standard deviation during the lead time period.

$\sigma_{L}$ can be calculated as the square root of the sum of the variances for each day during the lead time period:

$$
\sigma_{L}=\sqrt{\sum_{i=1}^{L} \sigma_{d_{i}}}
$$

where $d_{i}$ is the standard deviation for each day during the lead time period.

It is to be remembered here that while calculating the total cost has two components. The first one is the variable component of the total cost that is related to the Figure 4 and the second one is the fixed component of the total cost that is related to the safety stock shown in Figure 5.

\section{Example Problem}

Considering the pertinent data available from a firm, the following values are taken for consideration.

The annual demand for the product $(D): 24000$ units. The set up cost $\left(C_{0}\right)$ per set up for direct manufacturing: Rs.100.

The set up cost $\left(C_{0}^{1}\right)$ per set up for remanufacturing: Rs.60.

The holding cost for the finished goods in direct manufacturing with remanufactured items $\left(C_{1}\right)$ : Rs.10 per unit per year.

The holding cost for the goods in remanufacturing cycle: Rs.6 per unit per year.

The fraction return for remanufacturing $(f)$ : within the range of 0.1 to 0.9 .

Using these values in (17) and (20) with a range of values for fraction return of used goods for remanufacturing the

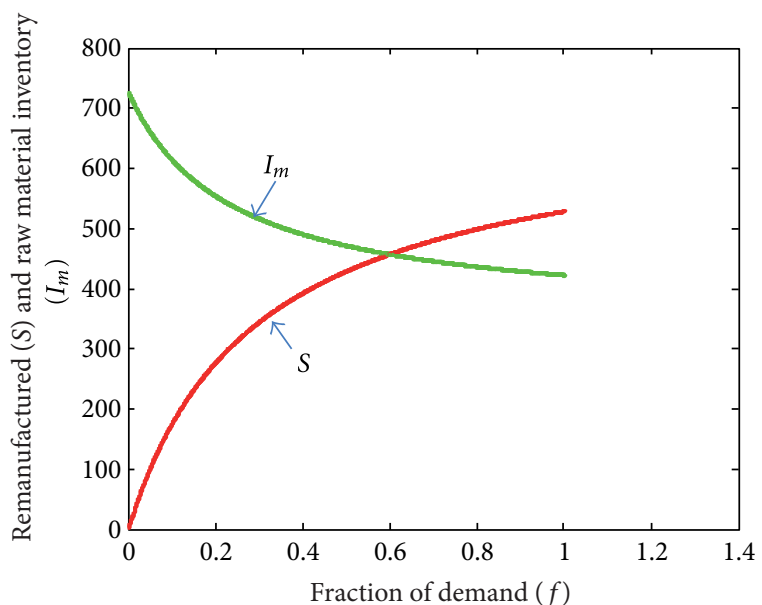

FIGURE 6: Variation of remanufactured quantity and raw material inventory with fraction of demand.

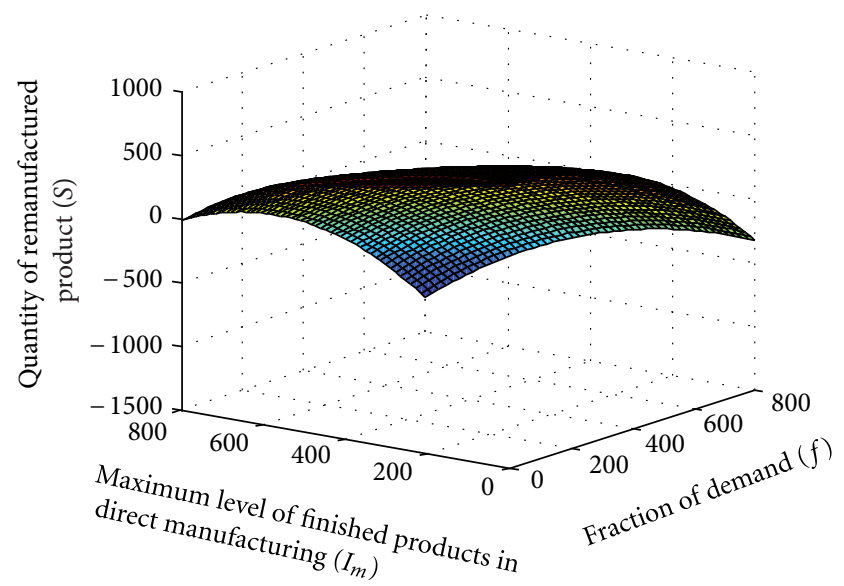

FIGURE 7: The variation of quantities for direct manufacturing and remanufacturing with change in fraction of demand return.

associated values of " $I_{m}$ " and " $S$ " can be calculated and using the values of " $I_{m}$ " and " $S$ " along with the given values in (15), the total costs is computed as shown in Table 1.

\section{Results and Analysis}

The results obtained from the calculations are shown in Table 1. The inter-relationship between the various parameters is shown in Figures 6, 7, and 8. Looking at the values of the total cost, it is evident that the total cost decreases with the increase in the fraction return for remanufacturing $(f)$. Figure 6 shows the variation of $I_{m}$ and $S$ with the fraction of demand returned for remanufacturing. The variation $S$ with $f$ shows that the rate of increase in $S(\Delta S)$ decreases with increase in the $f$ value. The variation of $I_{m}$ shows that the rate of decrease in $I_{m}\left(\Delta I_{m}\right)$ decreases with increase in the $f$ value. The values of $I_{m}$ and $S$ almost agree at $f=0.6$.

Figure 7 shows the variation of remanufactured quantity and the maximum level of the inventory in direct manufacturing with change in the fraction of demand return. The 


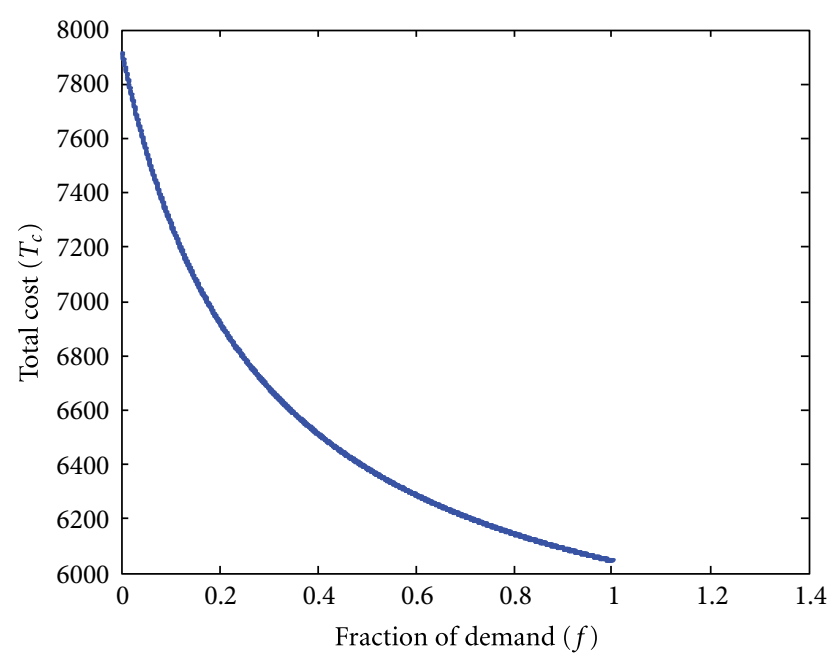

FIgURE 8: The variation of total cost with fraction of demand.

exponential nature of the curve shows the decrease in the values of these parameters at both the ends, that is, at the maximum values of the parameters and the minimum values of the parameters. This indicates the optimal level of the parameters that can be chosen for better return on investment and the increased productivity.

Figure 8 shows the variation of total cost with fraction of demand. The exponential nature of the curve shows the decrease in the total cost decreases at a decreased rate with increase in the " $f$ " value.

The major factor in the proposed model is the fraction return for remanufacturing. This factor varies depending on the type of industry the type of product and therefore it is very difficult to quantify. All the returned items cannot be remanufactured. Remanufacturing depends on the condition of the returned item as shown in Figure 1. So the major limitation is $100 \%$ remanufacturing is not attainable. Therefore, one needs to set the values of $I_{m}$ and $S$ depending on the type of industry and closely analyzing its return percentage for remanufacturing.

\section{Conclusions}

Decreasing profit margins in global markets with overcapacity together with increased returns that will be expensive to handle, if products and business processes have not been designed to accommodate them, will lead to huge losses. Companies will realize that they need a lifecycle approach to products, that is, an approach that integrates all product returns (commercial returns, warranty returns, repairs, endof-use returns, and end-of-life returns) into the business model for the product.

Once the reverse supply chain becomes the dominant factor in modern manufacturing, the productivity as a whole will find an increasing trend. The input resources to the production system can be brought with less cost in the form of returned items for remanufacturing. This will increase the productivity as the cost of input resources will decrease. The scope and application of reverse supply chain is actually too vast to be discussed here because of the limitations of space. This paper has only explored the remanufacturing part with certain assumptions in order to making the readers understand the activities under reverse supply chain. The purpose of this paper is to make the readers familiar with the field of reverse supply chain with remanufacturing. The discussed model has taken care of the remanufacturing aspect of reverse supply chain with the development of a mathematical model. The method for determination of optimum quantity for the remanufactured products and the directly manufactured products are illustrated with the help of a simple numerical example.

The readers are requested to study this carefully and use this model for further analysis. This can be taken as a base model to explore and develop a probabilistic model, in the field of reverse supply chain with remanufacturing. Readers can add different dimensions of reverse supply chain such as recycling to this model and check its feasibility.

\section{References}

[1] L. Brennan, S. M. Gupta, and K. N. Taleb, "Operations planning issues in an assembly/disassembly environment," International Journal of Operations \& Production Management, vol. 14, no. 9, pp. 57-67, 1994.

[2] R. Frankel, "The role and relevance of refocused inventory: supply chain management solutions," Business Horizons, vol. 49, no. 4, pp. 275-286, 2006.

[3] Arshinder, A. Kanda, and S. G. Deshmukh, "Supply chain coordination: perspectives, empirical studies and research directions," International Journal of Production Economics, vol. 115, no. 2, pp. 316-335, 2008.

[4] E. A. Silver, "Inventory management: an overview, Canadian publications, practical applications and suggestions for future research," INFOR, vol. 46, no. 1, pp. 15-28, 2008.

[5] H. K. Alfares, "Inventory model with stock-level dependent demand rate and variable holding cost," International Journal of Production Economics, vol. 108, no. 1-2, pp. 259-265, 2007.

[6] I. Dobos and K. Richter, "An extended production/recycling model with stationary demand and return rates," International Journal of Production Economics, vol. 90, no. 3, pp. 311-323, 2004.

[7] Y. H. Oh and H. Hwang, "Deterministic inventory model for recycling system," Journal of Intelligent Manufacturing, vol. 17, no. 4, pp. 423-428, 2006.

[8] S. G. Koh, H. Hwang, K. I. Sohn, and C. S. Ko, "An optimal ordering and recovery policy for reusable items," Computers and Industrial Engineering, vol. 43, no. 1-2, pp. 59-73, 2002.

[9] M. C. Mabini, L. M. Pintelon, and L. F. Gelders, "EOQ type formulations for controlling repairable inventories," International Journal of Production Economics, vol. 28, no. 1, pp. 21-33, 1992.

[10] K. Richter, "The EOQ repair and waste disposal model with variable setup numbers," European Journal of Operational Research, vol. 95, no. 2, pp. 313-324, 1996.

[11] K. Richter, "The extended EOQ repair and waste disposal model," International Journal of Production Economics, vol. 45, no. 1-3, pp. 443-447, 1996.

[12] R. H. Teunter and D. Vlachos, "On the necessity of a disposal option for returned items that can be remanufactured," International Journal of Production Economics, vol. 75, no. 3, pp. 257-266, 2002. 
[13] R. Teunter and E. Van der Laan, "On the non-optimality of the average cost approach for inventory models with remanufacturing," International Journal of Production Economics, vol. 79, no. 1, pp. 67-73, 2002.

[14] K. Richter and M. Sombrutzki, "Remanufacturing planning for the reverse Wagner/Whitin models," European Journal of Operational Research, vol. 121, no. 2, pp. 304-315, 2000.

[15] S. L. Chung, H. M. Wee, and P. C. Yang, "Optimal policy for a closed-loop supply chain inventory system with remanufacturing," Mathematical and Computer Modelling, vol. 48, no. 5-6, pp. 867-881, 2008. 

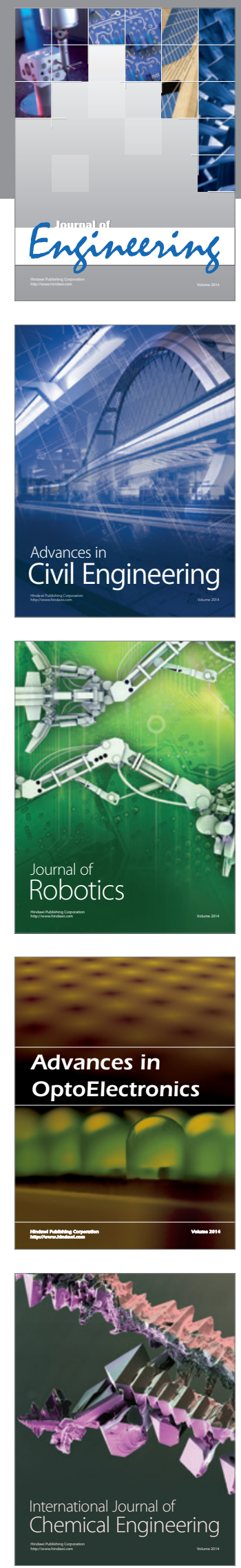

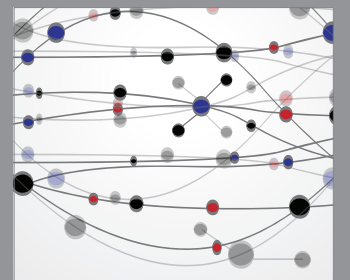

The Scientific World Journal
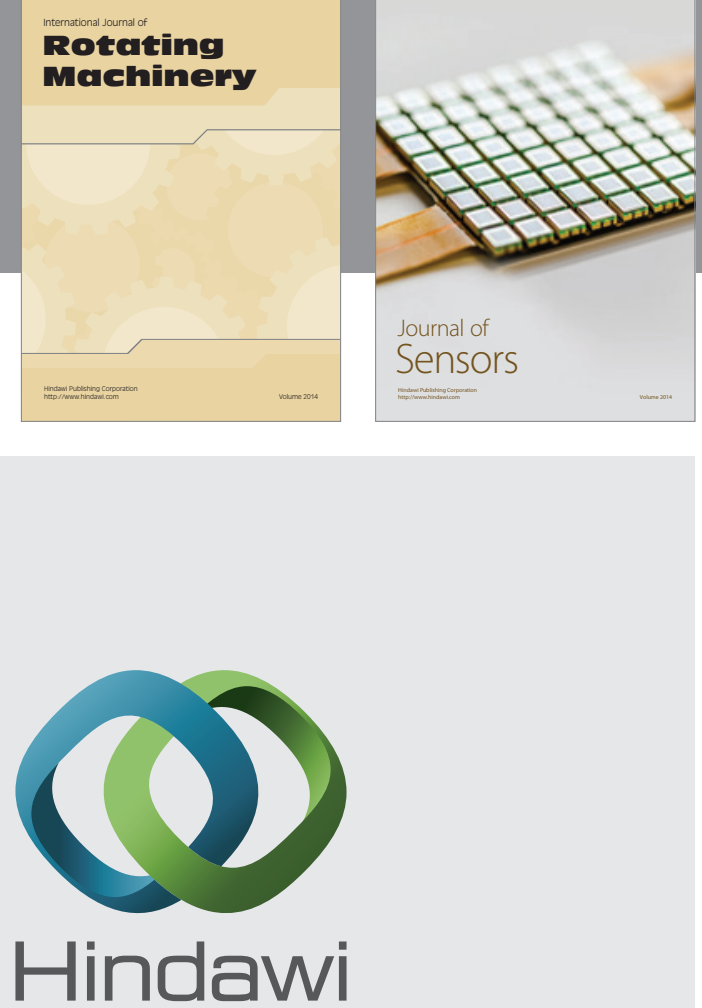

Submit your manuscripts at http://www.hindawi.com
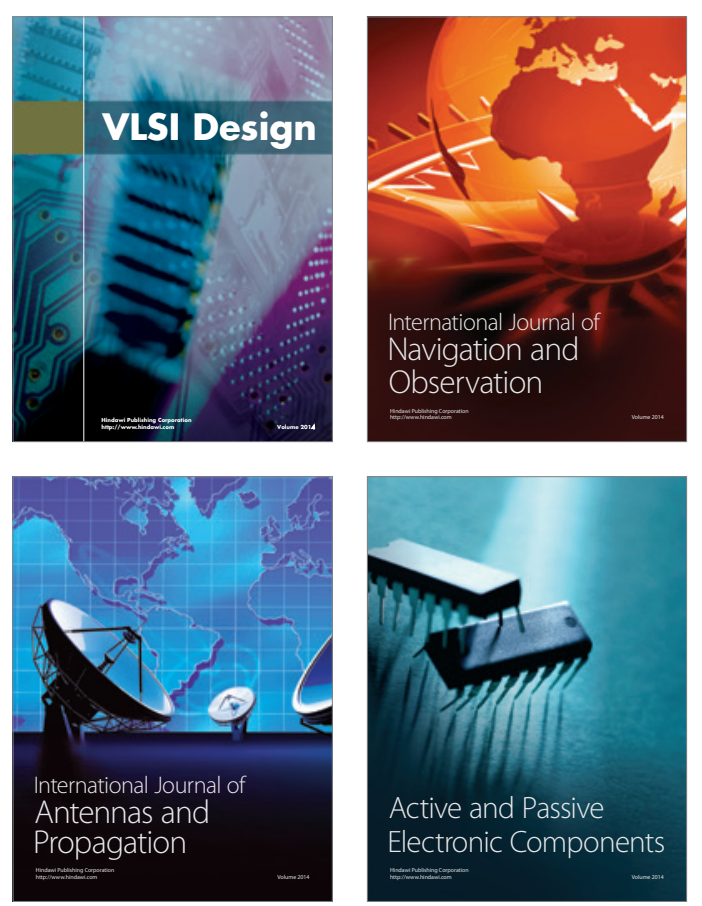
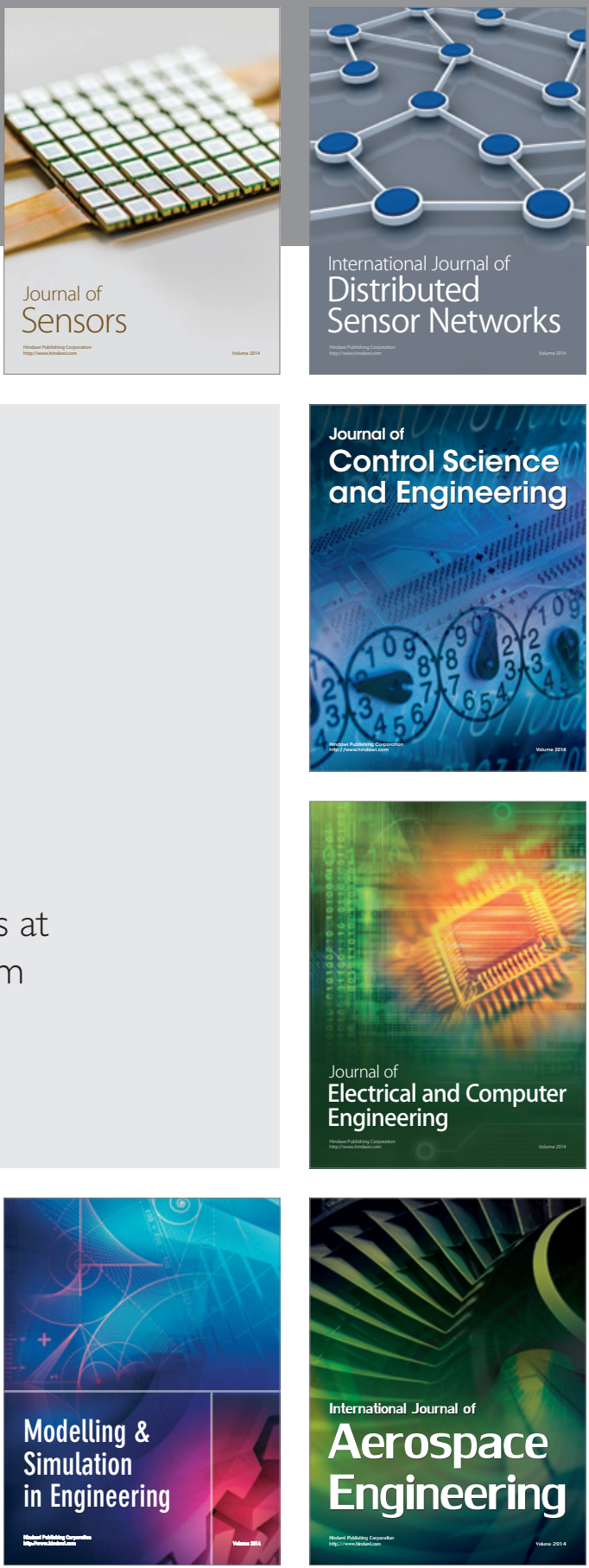

Journal of

Control Science

and Engineering
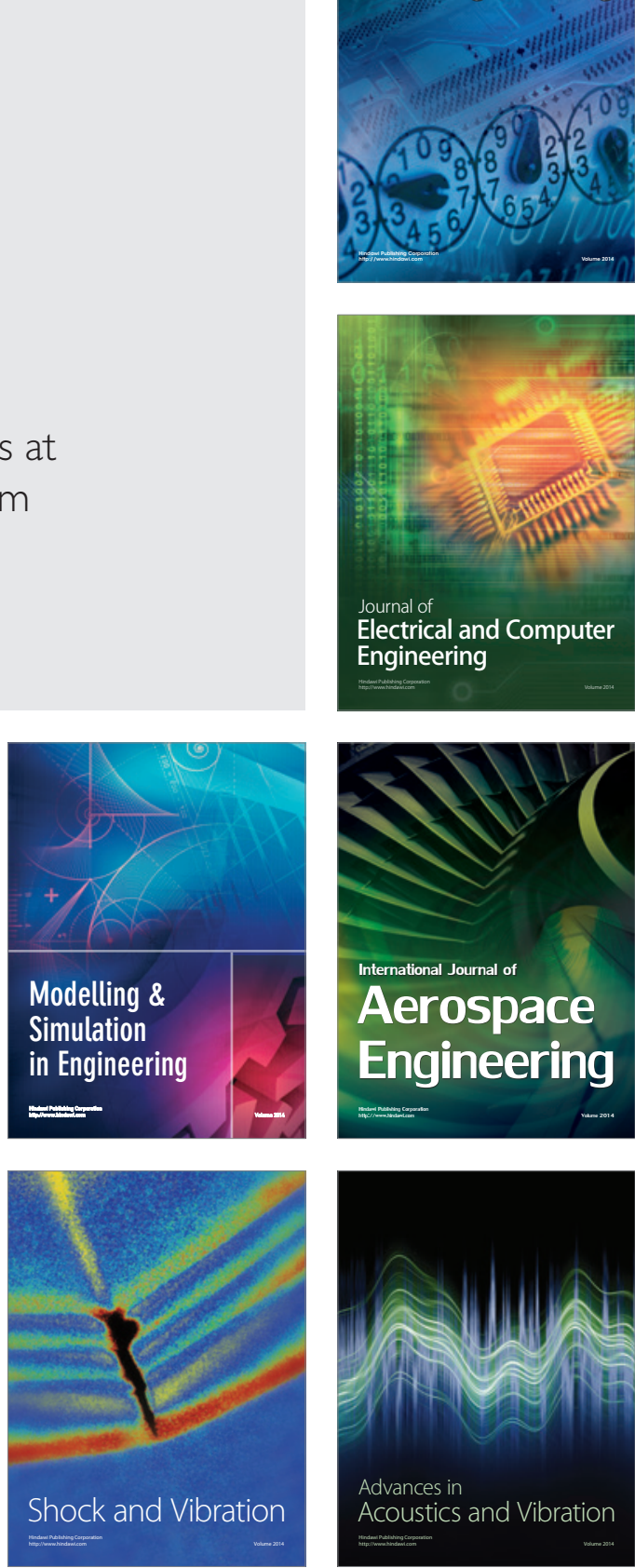